Fecha de recepción: diciembre 2017 Fecha de aceptación: marzo 2018

Versión final: julio 2019

\section{Aprender a verse como una marca. El cálculo, tiempo y ethos en Argelia 60}

Bárbara Guerschman *

Resumen: El objetivo de este artículo consiste en describir el proceso por el cual un grupo de diseñadores de indumentaria son reconocidos como marcas por otros agentes en el campo de la moda con quienes se vinculan para confeccionar, exhibir y comercializar sus colecciones de temporada: modelistas, asesores en marketing, estilistas, productores de desfiles y dueños de tiendas multimarcas.

Mi propósito es comprender de qué formas, en el curso de este proceso, los diseñadores incorporan el "cálculo" en su conducta como una ética que, según la define Pierre Bourdieu, es constitutiva de la economía capitalista e implica la percepción temporal del futuro distanciada del presente inmediato que caracteriza las economías precapitalistas. Teniendo en cuenta mi trabajo de campo etnográfico realizado entre 2005 y 2018, analizaré cómo ellos aprehenden dicha ética al comercializar las colecciones, en espacios como los locales de venta al público, las tiendas multimarcas y los eventos bianuales de moda.

Palabras clave: cálculo - tiempo - moda - diseño - colección - Argelia 60.

[Resúmenes en inglés y portugués en las páginas 174-175]

${ }^{(*)}$ Magister en Antropología Social (IDES - IDAES - UNSAM) y licenciada en antropología social (UBA). Docente de grado en la carrera de Psicología en la Universidad de Belgrano y la carrera de Antropología en la Universidad de Buenos Aires. Estudia temáticas ligadas al cuerpo, la moda y el diseño. Específicamente, en la maestría y doctorado, analiza la participación de un grupo de diseñadores de indumentaria en eventos de moda y desfiles de temporada. Ha intervenido con publicaciones y capítulos en compilaciones, congresos y jornadas de Sociología y Antropología. barbara.guerschman@gmail.com

\title{
Introducción
}

A comienzos del 2005 y por más de una década, he desarrollado mi trabajo de campo etnográfico que incluyó la realización de entrevistas abiertas a diseñadores de indumentaria: mujeres y hombres recibidos de carreras de diseño y provenientes de otras profesiones como administración de empresas, artes plásticas o arquitectura. Sus colecciones com- 
prendían principalmente prendas de vestir sumado a calzado, artículos de marroquinería y piezas de joyería.

Sumado a las entrevistas, llevé a cabo observaciones en locales de venta al público situados en los barrios de Palermo y Retiro, así como en puestos y desfiles realizados en dos eventos públicos organizados en CABA: el BAF Week (abreviación de "Buenos Aires Fashion Week") y "Puro Diseño". El primer evento es bianual e incluye la exhibición de colecciones de indumentaria en desfiles y stands, en correspondencia con la realización de las "semanas de la moda" en diferentes ciudades. La segunda feria es anual e incluye puestos en los cuales se comercializa indumentaria, mobiliario y objetos de decoración.

En el curso de mis encuentros con los diseñadores, al preguntarles cómo se consideraban a sí mismos, ellos no solían expresar: fundé una empresa, soy un empresario o un emprendedor. Por el contrario, señalaban: soy una marca de diseñador, pero no soy una marca comercial o de shopping. A medida que avanzaba en la investigación, advertí que estas distinciones eran igualmente reafirmadas por periodistas y editores de moda en sus ensayos y reseñas de revistas ${ }^{1}$.

La marca y el diseñador operaban como categorías de adscripción que, en determinadas situaciones, los informantes oponían entre sí y en otras, las articulaban para indicar el proceso en el cual estaban implicados: soy un diseñador que estoy en camino de ser una marca. Respecto a la realización de las colecciones, constituirse como una marca significaba incrementar progresivamente la cantidad producida de prendas por modelos de temporada a temporada.

La diferencia entre las marcas y los diseñadores se expresaba además en el número de locales de venta al público. Mientras que una marca de shopping detentaba al menos cinco locales en los centros comerciales y la vía pública; el diseñador contaba generalmente con un único local en ésta última (en los periodos de mayor expansión, llegaba a sostener dos) o un showroom instalado en un departamento o casa donde comercializaba la vestimenta y, en algunas ocasiones, dictaba cursos de moldería y sastrería a estudiantes de diseño.

En la trayectoria de estos diseñadores, se alternaban ciclos en los cuales incrementaban los volúmenes de producción o los reducían, abrían y cerraban negocios en diferentes barrios. En ciertas épocas, realizaban sistemáticamente colecciones de temporada y en otras dejaban de hacerlo para confeccionar una determinada cantidad de prendas a fin de cumplir con el pedido puntual de un cliente.

Sumado a las modificaciones en los volúmenes de producción y la cantidad de locales, los diseñadores se diferenciaban de las marcas comerciales respecto a la copia de tendencias. Con este término, designaban la apropiación de los estilos de vestir y la selección de tonos en una paleta de colores de una temporada que las marcas reproducían en la moldería ${ }^{2}$ de la colección. Estos estilos de vestir provienen de ciudades reconocidas como "centros" o "capitales" de la moda -las cuatro más reconocidas son Paris, Nueva York, Tokio o Londres- y se difunden a otras urbes ${ }^{3}$. Esta difusión instaura un desfase temporal y espacial entre los hemisferios norte y sur lo cual significa que, cuando en algunas ciudades, las empresas exhiben las colecciones de primavera-verano del 2018, en las pasarelas de desfiles realizados en otras urbes ya se anticipa el otoño-invierno del 2019.

Llegar a ser una marca implicaba tener en cuenta las tendencias al planificar una colección y, como expresión de tal influencia, quienes estaban a cargo de tal planificación llevaban a 
cabo los viajes de producto a los centros indicados para adquirir información sobre las tendencias. Desde la perspectiva de los diseñadores, las marcas comerciales se caracterizaban por replicar las tendencias de forma literal, una réplica que estaba ausente en el desarrollo de sus propias colecciones. Aun reconociendo la influencia de las tendencias, aclaraban que no las copiaban sino que las adecuaban a su identidad. Los diseñadores objetaban pues la copia en su propia producción, estableciendo una distancia moral respecto a las marcas comerciales. Si bien reconocían estar involucrados en un proceso que los llevaba a ser marcas, enfatizaban que el mismo no los constituía en marcas de shopping ${ }^{4}$. Teniendo en cuenta lo señalado, el objetivo de este artículo consiste en comprender cómo estos diseñadores se reconocen, a la vez que son instituidos como marcas en el campo de la moda ${ }^{5}$. Tal intervención implicaba, en algunos casos, ofrecer servicios de asesoramiento comercial como es el caso de Mariela ${ }^{6}$ :

Mariela: muchos diseñadores tienen que verse como marcas para empezar a trabajar como marcas

Bárbara: ¿qué implicaría verse como marcas?

Mariela: ser responsables en cuanto a pensar un proyecto coherente porque, a veces, el diseñador vuela en el diseño entonces pierde el contacto con el consumidor. El diseño es espectacular pero no conseguís quien te lo compre porque tuvo que ver con un vuelo propio del diseñador, eso ya es ser un artista ¿no? [tras unos instantes, agrega] los ayudo a definirse como artistas o marcas, si vos vendés al consumidor final y tenés varios locales, probablemente ya estés hablando de ser una marca, si querés que tu producto sean piezas únicas, casi como piezas de arte, entonces estás más para ser una galería de arte que una marca ¿entendés?

Para llevar a cabo el artículo, me basaré en conceptos desarrollados en "Argelia 60" donde Bourdieu (2006) detalla la transición de una sociedad tradicional a una sociedad moderna a partir del análisis de dimensiones tales como la previdencia y previsión, el cálculo, el ethos y el calendario. Los artículos incluidos en "Argelia 60" están basados en el trabajo de campo etnográfico que el autor llevó a cabo en el norte de Argelia, entre 1958 y 1961, tras prestar servicios militares para el Estado Francés. Su trabajo de campo fue realizado en la región de Cabilia, con campesinos cabilios, en el contexto de un proceso de descolonización producido en ese país. Inspirada en los avatares que este proceso significaba para los cabilios, me propongo mostrar la vigencia de estas dimensiones a la hora de pensar en cómo los diseñadores, a medida que formalizan su emprendimiento, se apropian y reactualizan las dimensiones señaladas por Bourdieu. En otras palabras, ¿ cómo el ethos, que el autor define como una ética o conducta, es incorporado al producir y vender vestimenta? En la siguiente sección presento a los diseñadores: las instituciones y empresas en las cuales se formaron y trabajaron así como el desarrollo de sus colecciones. La segunda parte trata sobre la noción de cálculo desde la perspectiva de Pierre Bourdieu y Michel Callon. En la tercera parte desarrollo la temática de la temporalidad respecto a la organización de los calendarios. En la última sección y teniendo en cuenta lo analizado en secciones previas, describo la realización del concurso "Buenos Aires Diseña" realizado por el $\mathrm{CMD}^{7}$, 
una institución que brinda ayuda económica a los concursantes para llevar a cabo los desfiles en el BAF Week, que es uno de los eventos donde llevé a cabo las observaciones en el curso de mi trabajo de campo.

Desde la perspectiva bourdesiana, el campo consiste en un espacio de posiciones que se definen por lo que está en juego, por la distribución del capital específico que vale sólo dentro de dicho espacio. El capital específico en la moda y el arte consiste en el poder de constituir los bienes como "raros" a partir del efecto que produce la firma del creador en ellos: es una marca que no altera su naturaleza física o material sino su naturaleza social, lo cual significa que se incrementa su valor como fetiche, legitimando a quien lo creó (Bourdieu 1990).

En torno a la apropiación del capital específico, la competencia se entabla entre los agentes recién llegados y quienes se incorporaron hace más tiempo, por lo cual acumularon mayor capital. Los recién llegados deben pagar un derecho de admisión y conocer cuáles son los principios del juego, apelando a estrategias de herejía a fin de subvertir la escala de valores imperante para concretar tal acumulación. Los participantes más antiguos recurren a estrategias de conservación para mantener intactos los principios del juego y, al mismo tiempo, sostenerse ellos mismos en éste.

En "Alta Costura y Alta Cultura", Bourdieu distingue a los diseñadores o couturiers como los principales agentes de la moda pero otorga una menor importancia a la intervención de los agentes o instituciones en la alta costura francesa. Respecto a ésta última, la socióloga Agnes Rocamora (2002) comenta que Bourdieu, no le presta la debida atención al desarrollo de la moda masiva, el subcampo de la gran producción contrario al subcampo de la producción restringida 8 .

Más allá de la innegable participación de los productores de vestimenta que son los diseñadores, Rocamora señala la intervención de los "intermediarios culturales" de la burguesía que, como señala Bourdieu (1998) en "La Distinción”, desempeñan profesiones de presentación en instituciones dedicadas a la venta de bienes y servicios simbólicos: representantes de comercio y publicitarios, especialistas en relaciones públicas, moda y decoración; producción y animación cultural así como presentadores y periodistas. Estos agentes intervienen en el campo intelectual y artístico, en instituciones de consagración y difusión otorgando valor a las obras: las academias y los salones, las casas editoriales y asociaciones culturales y científicas, los teatros, cenáculos, los círculos de críticos y el sistema escolar que incluye a los profesores.

En lo que respecta al trabajo de campo etnográfico realizado, la mayor parte de los diseñadores (son los productores directos dentro del campo) estudiaron en carreras de diseño de indumentaria y moda impartidas en instituciones privadas y públicas. Una de éstas es la carrera de DIT (Diseño de Indumentaria y Textil) dictada en la Facultad de Arquitectura, Diseño y Urbanismo de la UBA. De forma paralela a la cursada-incorporándose al sistema escolar señalado- algunos se inscribieron en cursos de moldería, sastrería y confección dictados en las mismas carreras o institutos privados.

Siendo estudiantes o ya recibidos, la mayor parte de los diseñadores se emplearon en el departamento de producto de marcas, donde se ocupaban del desarrollo de las colecciones. En esta etapa -trabajar en producto- realizaban los bocetos de las prendas en función de los cuales las modelistas desarrollaban las bases de moldería. Asimismo, recorrían los 
talleres de corte y costura, los talleres de muestristas, zapateros así como los negocios de la marca donde trabajaban acomodando las prendas de las vidrieras. Al rememorar este trabajo, los diseñadores destacaban que debían replicar la información traída por sus jefes del viaje de producto: catálogos o prendas compradas en tiendas departamentales.

Luego de la renuncia o habiendo sido despedidos, los diseñadores iniciaron sus propias colecciones que incluían inicialmente 15 o 20 modelos para luego aumentar esta cantidad. Como señalé, las trayectorias de los diseñadores incluyeron periodos donde incrementaban el volumen de producción, inauguraban locales así como participaban en desfiles y ferias. En otros periodos, dicho volumen mermaba, cerraban locales o incluso la misma marca. Para confeccionar la vestimenta, recurrían a proveedores de tejidos, avíos (cierres, botones y ferrerías) y talleres de diferentes especialidades situados en CABA y el conurbano: moldería, muestras, corte y costura. Sumado a su propia producción, algunos diseñadores ofrecían a otras marcas lo que se denomina producto terminado, encargándose de la elaboración de una prenda que incluía la moldería, los prototipos y la costura en sus propios talleres o externos.

Respecto a la comercialización, los diseñadores inicialmente consignaban en tiendas multimarcas cuyos dueños exhibían las prendas hasta ser vendidas, en función de lo cual les pagaban un monto que incluía un porcentaje adicionado al precio de venta. En caso de no venderse, los dueños se las devolvían al cabo de unos meses. La consignación también se realizaba en ferias permanentes o esporádicas, organizadas en domicilios particulares. Otro espacio de comercialización era el propio showroom o local de venta al público. A este espacio (es la clienta que entra al local y te compra una o dos prendas, como lo describió una entrevistada) los diseñadores lo asociaban con la venta minorista mientras que la venta anticipada a tiendas multimarcas situadas en ciudades de Argentina o el exterior se llamaba mayorista. Una de las modalidades para atraer y entablar tratos comerciales con los clientes mayoristas era participando en rondas de negocios organizadas en ferias de moda en CABA y ciudades del exterior del país donde participaban en desfiles de temporada y/o instalando un puesto.

Para llevar a cabo los desfiles, los diseñadores recurrían a un estilista o productor (en varias situaciones, eran la misma persona ${ }^{9}$ ) con quienes resolvían cual sería el concepto de la exhibición vinculado con el concepto de la colección materializado en el lookbook ${ }^{10}$. El productor se ocupaba de contratar a su equipo de maquilladores, peinadores, iluminadores y musicalizadores así como asistentes de vestuario y los agentes de prensa que elaboraban la lista de invitados a la primera fila frente a la pasarela: modelos, celebridades, periodistas y editores de moda. En el BAF Week, los servicios de los productores eran contratados por sus organizadores.

En el concurso "Buenos Aires Diseña" organizado por el CMD los finalistas -quienes debían ser estudiantes avanzados de carreras de diseño- obtenían los servicios de productores junto con una suma de dinero para costear la confección de las prendas exhibidas en la pasarela del BAF Week. Para participar, presentaban bocetos y muestras de tejidos de la colección de temporada ante un jurado conformado por jefes de producto de marcas, fotógrafos, estilistas o directores de carreras dictadas en universidades privadas y públicas. Tras el desfile, debían asistir a una serie de reuniones, con personal de la institución para recibir asesoramiento sobre gestión en negocios. Los concursantes podían presentarse al 
concurso en tres instancias: "emergente", “emergente bis" y "consagrado". Para la primera, debían presentar una serie de documentos, sumado a los prototipos de algunas prendas: la fotocopia del DNI, constancia de inscripción en la AFIP (Administración Federal de Ingresos Públicos) y el certificado analítico de materias aprobadas.

Teniendo en cuenta el capital específico en la moda, los diseñadores compiten por el poder de otorgar valor a la vestimenta instituyendo a la misma como un fetiche, incrementando el valor de la firma de sus creadores. Esta competencia se lleva a cabo en instituciones donde diferentes intermediarios imponen sus normas estéticas como "taste makers".

Respecto a la comercialización, los dueños de la tiendas multimarca compran o consignan prendas. En este sentido, Silvana, la dueña de una tienda situada en el barrio de San Telmo, seleccionaba a los diseñadores asignándoles un perchero evaluando la originalidad de sus colecciones, que en éstas pudiera identificarse un concepto y fueran vendibles, desde su perspectiva, lo cual significaba que pudieran venderse a precios competitivos a los consumidores. Mariela puede ser considerada igualmente una intermediaria y "taste maker" en un sentido que su asesoría implica una valoración acerca de cómo exhibir y vender los bienes.

En los desfiles o las producciones fotográficas, los estilistas o productores asumen decisiones estéticas y operativas respecto al curso de las pasadas ${ }^{11} \mathrm{o}$ tomas realizadas por las modelos. Por un lado, deciden cuál es el concepto y cómo expresarlo en el desfile o sesión fotográfica. Por otro lado, se ocupan de montar la escenografía y resolver la coreografía de las pasadas en conjunción con la música e iluminación. Es preciso señalar además la concurrencia de periodistas y celebridades que, al ser convocados por agentes de prensa, legitiman con su presencia o escritos tal desarrollo.

El capital específico dentro del campo de la moda consiste en el poder de otorgar valor a la vestimenta y que la misma sea reconocida por otros agentes o instituciones. Para comprender cómo se asigna tal valor o rareza, en relación al reconocimiento del diseñador como marca, es preciso trascender la dimensión artística. Esto significa considerar a la moda como un campo económico en el cual los agentes son las empresas que pugnan por apropiarse de diferentes formas de capital. En lo relativo al capital simbólico específico de este campo, consiste en el reconocimiento de la imagen de marca, la fidelidad otorgada a la misma por los compradores (Bourdieu 2000).

La moda se encuentra en un espacio intermedio entre el espacio económico y el artístico lo cual significa que en ella prevalecen las reglas relativas a la apreciación estética de una obra, la creencia colectiva que constituye un fetiche y que su creador adquirió dotes mágicas para realizarla. Al mismo tiempo, es un campo donde rige el enunciado "los negocios son negocios" y los precios constituyen armas en un juego donde se disputa el capital específico dentro del campo económico. Desde la perspectiva bourdesiana, en la moda se compite por la rareza que otorga la firma al creador quien, a su vez, se identifica como marca y pretende ser considerado como tal por otros agentes (empresas, consumidores e intermediarios culturales). Desde la perspectiva de los diseñadores, ellos pretendían ser reconocidos como autores y que fuera reconocida la diferencia entre la producción de sus colecciones y la copia de tendencias. 


\section{El cálculo}

En la "Ética protestante y el espíritu del capitalismo", Max Weber (1993) describe cómo los ideales religiosos del protestantismo ascético influyeron en la formación de un ethos económico que comprende un conjunto de máximas morales de conducta cuya infracción genera inconvenientes en la formalización de negocios a la vez que constituye una omisión al deber. Retomando estas nociones en "Argelia 60", Bourdieu define la ética como una finalidad que permite la adaptación a un orden a partir de la transmisión de saberes. El tipo de cálculo realizado para adaptarse a la economía capitalista se diferencia de aquellos saberes necesarios para adecuarse a la economía precapitalista. En esta última prevalece la "previdencia" que consiste en la preocupación por adecuarse a modelos heredados en una existencia signada por la inseguridad, lo provisorio y el capricho del azar. Lejos de pretender disciplinar la naturaleza, el campesino argelino cabilio se somete a potencias que considera mágicas como los ciclos orgánicos.

A la conducta del campesino -que consiste en ofrecer el menor asidero posible al futuroel autor la define como el tradicionalismo que, en las ciudades, se encuentra presente en el artesanado y el comercio. En estos islotes aislados de la competencia económica, el reclutamiento de los trabajadores se produce en base a los lazos de parentesco dentro de empresas familiares donde prevalece una atávica resistencia a alterar hábitos de pensamiento y el patrón se ocupa de comprar las materias primas, fijar el precio de las mercancías y supervisar su venta.

En la economía capitalista, en cambio, impera la lógica de la "previsión" que consiste en la capacidad de divisar por anticipado un futuro abstracto, distanciado de lo tangible y presente. Contrariamente a la resistencia a cambiar los hábitos que prevalecen en el artesanado y comercio, el cálculo racional supone que los agentes introduzcan innovaciones en las técnicas productivas para lo cual deben racionalizar la conducta trascendiendo el tradicionalismo señalado, desligando la instancia del trabajo de la instancia de producción, una separación que está ausente en la economía agrícola.

Sin ánimo de llevar adelante una interpretación lineal del instrumental teórico bourdeano en su lectura Cabilia, se mostrará cómo los diseñadores -a medida que se transforman en marcas- necesitan ajustar sus prácticas a una demanda externa de mayor racionalización en el sentido bourdeano expuesto en Argelia 60. Una de las formas en las cuales se procura trascender el presente inmediato en las sociedades capitalistas; más precisamente en el campo económico donde participan los diseñadores como propietarios de empresas (aunque ellos se identifican como marcas) es a través del "plan de negocios": un modelo donde se explicita el curso a seguir en la prosecución de escenario futuro que es un emprendimiento o empresa. Tomando en consideración una guía de negocios para PYMES editada por la institución a cargo del concurso "Buenos Aires Diseña", una de las instancias significativas del plan indicado es determinar quiénes serán los consumidores de las vestimentas dentro de un determinado mercado, y cuáles son las presuntas necesidades que el diseñador estaría satisfaciendo al producirlas. Expresado en otras palabras, al elaborar el plan se procura dominar la incertidumbre y alejarse de lo tangible e inmediato.

Como acción racional, el cálculo constituye una práctica colectiva que comprende una serie de operaciones que el sociólogo económico Michel Callon (1998) describe preten- 
diendo superar la distinción entre lo cuantitativo y cualitativo. Debido a que los agentes precisan obtener información de los estados del mundo, establecen una lista y jerarquías de estos posibles estados o cosas (actores y bienes) para establecer cursos de acción posibles. A partir del cálculo se genera un resultado: una lista, evaluación, la formulación de un algoritmo o serie de juicios sobre algo.

Según Marina, que los diseñadores aprendieran a verse como marcas suponía distanciarse de su condición de artistas avizorando un determinado consumidor. La proyección de un consumo futuro, como curso de acción a seguir, propuesto en el manual de negocios constituye uno de los principios del marketing como disciplina performativa: al delimitar un mercado al cual dirigirse con un producto, éste se instituye como realidad (Gilles Marion, 2006). Desde la perspectiva de la asesora, aquellos no vendían piezas artísticas sino mercancías en comercios. Es un enunciado que puede ser pensado como una máxima que compele a trascender el presente en vistas de un porvenir o bien que el diseñador se distanciara del subcampo de la producción restringida para incorporarse al subcampo de la gran producción donde prevalece la lógica del mercado.

$\mathrm{Al}$ describir el proceso de convertirse en marcas, los diseñadores señalaron los números como un aspecto que les resultaba difícil de encarar (argumentando que carecían de formación de negocios) por lo cual procuraban delegar su manejo en un conocido o familiar: un contador o administrador. Varios se describieron a sí mismos como un desastre al lidiar con los números; esto es, con cuestiones contables, calcular los precios, costos fijos y variables de las mercancías sumado a los puntos de equilibrio. Los números comprendían además la compra de materias primas e insumos así como el trato con proveedores. En su pequeño comercio, el islote presuntamente distanciado de la competencia, algunos diseñadores procuraban desligarse del manejo de los números si es que hallaban a alguien dispuesto a hacerlo.

¿Cómo se calculaban los precios como dimensión de los números? Se lo pregunté a Clarisa, la diseñadora que fundó -junto con Eduardo, su socio y pareja- la marca "Vestiré" en el 2001. Con ella me reuní en el 2016, en un bar próximo a su único local situado en el barrio de Palermo, en la calle Gurruchaga, atendido por un único vendedor. Clarisa replicó que habían elaborado una grilla en el programa informático "Excel", que comprendía un detalle del costo que suponía confeccionar cada artículo junto con los avíos y tejidos. En la grilla incluían asimismo los gastos relativos al pago de la modelista, el tallerista y los impuestos. Siete años antes, me entrevisté con Valentina, socia de la marca "Secta" junto con una artista plástica llamada Luciana. Mientras conversábamos en el local situado en Almagro, aquella señaló los costos de producir dentro de la marca:

Valentina: vos tenés los costos fijos ¿sí? Que tienen que ver con lo que sucede cotidianamente en la empresa, los gastos fijos mensuales y después tenés en cuenta el costo de confección, del material, los avíos y todo eso te da un número y en base a eso hacés una recarga. Tenés que tener en cuenta el packaging [embalaje en inglés] y la publicidad que vas a invertir en esa campaña, todo eso se paga en la prenda, o sea, son todas esas variables y después tenés en cuenta un costo inflacionario, hace tres años que venimos sufriendo una inflación importante. 
En la realización de la grilla se expresa el cálculo cuantitativo de los costos de las materias primas junto con los honorarios de las modelistas y las muestristas. Teniendo en cuenta lo señalado por Valentina, el aumento de los precios constituye una variable de la moneda que, según Bourdieu, representa un signo contable que anticipa un valor futuro. El mismo es empero cambiante en la Argentina debido a los ocasionales periodos inflacionarios que lo alteran sin lograr tal anticipación.

En la ponderación de los costos, los fijos se diferencian de los variables. De acuerdo a lo expresado en un sitio en Internet ${ }^{12}$, los primeros (salarios o alquileres) se costean independientemente del nivel de producción en un negocio o las ventas. Los segundos deben ser pagados para generar un producto o servicio como las materias primas y la mano de obra. El desarrollo de la colección no sólo comprende el señalado cálculo cuantitativo de costos sino dimensiones que son cualitativas. Teniendo en cuenta lo expresado por Vera ${ }^{13}$ en una conferencia dictada en el 2014 en el CMD llamada "Gestión de Moda", dicho desarrollo implicaba en primer lugar determinar cuál era el concepto que podía estar basado en un periodo histórico, una corriente artística, un color o estampa. A modo de ejemplo, Vivi señaló en el 2005 que su inspiración para desarrollar la colección era el tango. Teniendo en cuenta que la moda es un campo donde los bienes son evaluados por diversos agentes, no sólo es relevante que un diseñador anuncie cual es el concepto en una determinada temporada sino que el mismo sea legitimado por intermediarios; avalando públicamente que el concepto está fundado en el tango u otra fuente de inspiración.

Según relataron los diseñadores, sus colecciones se iniciaban a partir de la formulación de un concepto en torno al cual desarrollaban un conjunto de prendas dos veces en el año, por temporada. Si tenemos en cuenta la noción de cálculo según Bourdieu y Callon, la colección supone la articulación de una dimensión cualitativa que es el concepto basado en alguna fuente de inspiración y una dimensión cuantitativa (que comprende costos, precios, impuestos y salarios) materializadas en la elaboración de grillas, planillas y bocetos. La colección supone asimismo la anticipación colectiva del tiempo que describiré seguidamente.

\section{El tiempo}

En "Argelia 60", Bourdieu describe cómo los campesinos experimentan el paso de una sociedad tradicional a una moderna cuando, en su condición de trabajadores semi empleados, se trasladan desde los ámbitos rurales a condominios situados en la periferia de las ciudades. Este traslado supone desprenderse del asidero comunitario de la vida aldeana para habitar el espacio estructurado del departamento que requiere el pago regular del alquiler incorporando la premura del vencimiento fijo. Asimismo, la temporalidad de la vida rural está signada por un calendario mítico ritual que diferencia los momentos festivos del trabajo agrícola que transcurre entre estaciones. Para el campesino, el calendario supone adecuarse a un ritmo social que conlleva prohibiciones, proverbios y presagios. $\mathrm{Al}$ trasladarse al ámbito urbano, los trabajadores se diferencian entre sí en función de dos "umbrales" -el empleo permanente e ingreso regular- que posibilitan visualizar el futuro señalado. A medida que se asciende en la jerarquía social y se modifican las condiciones 
materiales de existencia, el trabajador que dispone de un empleo permanente amplía el campo de los posibles liberándose de la preocupación por la subsistencia.

En las sociedades conviven una multiplicidad de "tecnologías temporales": calendarios, cronogramas y relojes (Henry Rutz, 1992). La moda impone el propio calendario sobre los agentes que no se caracteriza actualmente por proverbios, presagios ni se guía por ritmos naturales, sino que impone el cálculo racional al visualizar un futuro que es el mismo advenimiento de las temporadas. Quienes habitan en las ciudades situadas en el hemisferio sur, según la geógrafa australiana Sally Weller (2007), experimentan una disyunción espacio-temporal respecto a la información sobre estilos provenientes de urbes ubicadas en el hemisferio norte. En relación a esta disyunción, una diseñadora rememoró su trabajo como asistente en el departamento de producto de una marca comercial:

Lina: las marcas comerciales hacen los famosos viajes de producto a Europa o Estados Unidos, que es la colección que va a llegar a la Argentina la próxima temporada, vos viajás ahora [la entrevista se llevó a cabo en julio del 2005] en realidad, se viaja antes para comprar prendas de invierno que va a empezar en marzo ¿entendés?...

Sumado a la novedad constante en los estilos de vestir, la moda se caracteriza por la anticipación constante que, como señalé previamente, supone un desfase temporal: mientras las marcas presentan una colección, anticipan la siguiente. Este calendario, que no es mítico ritual, se impone en la existencia de los agentes diferenciando las estaciones.

¿Cómo influye este calendario al producir la colección? Al reunirme con Lina durante la temporada de otoño-invierno, comentó que ya estaba vendiendo prendas de primaveraverano y exhibiendo los muestrarios a sus clientes de los multimarcas situados en ciudades del interior del país. Por su parte, Alejo, el jefe de producto de una marca de indumentaria femenina, destacó las dos fechas de entrega anuales refiriéndose tanto a la vestimenta producida para otros como respecto de su propio emprendimiento: otoño-invierno debía exhibirse en los locales en febrero-marzo, mientras que en agosto precisaba estar lista la temporada de primavera-verano. Quienes trabajan en marcas perciben internamente una aceleración en el transcurrir del tiempo semejante a la señalada por Edward Thompson (1989) respecto a la clase obrera inglesa en los albores de la revolución industrial:

Alejo: el que labura en producción tiene el stress y la presión ¡mama mía!. Producción es correr contra el reloj, yo le digo a [menciona el nombre de una persona que trabaja en una marca comercial] te voy a entregar el 30 de abril, tengo que correr hasta el 30 porque cargo las máquinas, hoy me faltó uno o se me rompió la aguja. El tiempo se va acortando porque lo que prometí para el 30, me doy cuenta que no llego. Al tipo que me entrega el hilado se le rompió la máquina y en vez de entregármelo hoy, me lo entrega dentro de una semana, a mí eso me genera más de una parada y una semana más en confección. Se me rompe una máquina en un taller o dos a la vez, o sea, lo que iba a hacer en un día, tengo que hacerlo en tres, es raro que puedas trabajar tranquilo. 
No son los tiempos de Alejo y Lina los que corren sino un ritmo social signado por las fechas de entrega expresadas en tecnologías. En relación a fecha puntual indicada por Alejo, quien disponía de un empleo regular, él gestionaba con premura el tiempo ajeno de los talleristas supeditados, a su vez, a los ritmos de otras marcas para la cual trabajaba la empresa donde desempeñaba el cargo de jefe de producto. Esta premura en el tiempo se imponía sobre los diseñadores, algunos de los cuales realizaban producto terminado para otras marcas para lo cual disponían de sus propios talleres aunque, en determinadas fechas de entrega, recurrían a talleres externos como Vivi:

Vivi: lo que me pasa es que tengo que presentar la colección en el BAF, a todos los que le produzco les pasa lo mismo que a mí ¿entendés? no con desfile sino un showroom dónde ponen la colección. Todos quieren tener todo una semana antes, impecable, y estoy corriendo porque todavía no tengo toda la producción, tengo que adelantar muestras ¿viste? Es un trabajo intensivo de juntarme con la modista sábados y domingos

La premura del tiempo se expresa en la comercialización, la cual no está desligada de la confección. Previamente aludí a la consignación en tiendas multimarcas como una forma de comercializar. Una de estas tiendas pertenecía a Silvana en la cual cuarenta diseñadores tenían sus propios percheros. Para Silvana, una marca profesional era aquella que le entregaba las colecciones a tiempo y sin defectos en la confección, siendo su queja principal los atrasos (que según los diseñadores ocurrían por demoras en los propios ritmos de los talleres de confección con los cuales trataban). Lo que fallaba era la sincronización del trabajo debido a alteraciones producidas en los ritmos de manufactura, como expresaba Thompson (1989) para otro momento histórico pero que bien podría aplicarse a la modalidad productiva imperante en el rubro analizado. Estas alteraciones incidían, en el caso de algunos consignantes que entregaban sus prendas a Silvana, en los ritmos de la comercialización que implicaban exhibir las prendas de temporada en los percheros en determinados meses del año.

\section{El concurso}

Una de las formas por las cuales los diseñadores podían aspirar a concretar los desfiles de temporada era participando en el concurso "Buenos Aires Diseña". Organizado anualmente por la oficina de moda del CMD, dicho concursso habilitaba a quienes resultaban seleccionados a presentarse en los desfiles del BAF Week. La inscripción para participar requería que los diseñadores entregaran documentación: el curriculum actualizado, la constancia de materias aprobadas o título en trámite (sólo podían participar estudiantes de carreras de carreras de diseño o recién recibidos) y un domicilio en CABA para recibir las notificaciones, el comprobante de inscripción a la AFIP como pequeño contribuyente (corresponde al pago mensual del monotributo) y la fotocopia de la primera y segunda hoja del DNI junto con la constancia del CUIL. Respecto a la colección, los aspirantes precisaban exhibir quince conjuntos de indumentaria, conformados cada uno por tres prendas. 
De los quince conjuntos, tres debían estar confeccionados como prototipos para presentar junto con material fotográfico de los conjuntos, geometrales, bocetos y figurines ${ }^{14}$.

Quienes se presentaban por primera vez en la categoría "emergente", debían contar con un espacio físico o virtual de venta y su marca debía tener entre un año y cinco de permanencia en el mercado. Como parte de la premiación, los finalistas obtenían el seguimiento de un estilista que concurría en cuatro encuentros previos a la presentación de la colección. En el día del desfile, quince modelos exhibían las prendas junto con los servicios de maquilladores, peinadores, musicalizadores, coreógrafos y la asistencia de un agente de prensa. Meses antes del desfile, los participantes comparecían ante un jurado conformado por directores de carreras de diseño, fotógrafos, periodistas, diseñadores que resultaron ganadores en ediciones anteriores del certamen y jefes de producto de empresas. Ante el jurado, mostraban los prototipos, detallando la forma de confeccionarlos y comercializarlos. Como criterios de selección, los miembros del jurado evaluaban cuan innovadora era la morfología ${ }^{15}$ de las prendas así como la factibilidad en la producción y venta. Algunas de las escenas estaban exhibidas en unos videos en los cuales los evaluadores formulaban indicaciones a los aspirantes: más o menos críticas o benévolas acerca de la calidad de los prototipos incluyendo el planchado, la terminación de los forros interiores y costura de las telas. Asimismo, les preguntaban cómo producirían y venderían el producto en caso de ganar el concurso, ponderando cuan innovadora era la propuesta en términos de la identificación del concepto.

Tras la realización del desfile, los finalistas debían asistir a un programa de asistencia en gestión de negocios. Como señaló Marco, un empleado del programa, si bien la asistencia era obligatoria para los ganadores, éstos no siempre asistían por lo cual debía convocarlos personalmente. La finalidad del concurso -según lo expresó Marco y Gastón, el estilista con quien me reuní- no consistía únicamente en presentarse en pasarela y obtener repercusión en los medios de comunicación - una instancia que los nativos denominaban prensa- sino trascender la instancia del evento para generar un producto que se insertara en un mercado generando en consecuencia un negocio.

Una vez seleccionados los finalistas, se les notificaba que disponían de veinte días para realizar la colección con los quince modelos pedidos. En este lapso, descrito por los concursantes como "agotador" en vista de la fecha límite, recibían sucesivas visitas de los productores que los asesoraban respecto a la selección de prendas para exhibir en las pasadas: las pruebas de vestuario, maquillaje y peinado. Era agotador para los finalistas porque, según Marco, aguardaban al resultado del concurso para recién iniciar la confección.

Lo primero que debo señalar del concurso es que lo organiza una institución estatal vinculada con varias administraciones públicas como la AFIP, el registro de personas y las universidades. Esta vinculación supone, debido al estar implicado el Estado, la concentración del capital económico basado en la recaudación unificada de impuestos (con la cual se abonan los servicios del estilista y su equipo) y el capital informacional que supone la acumulación y redistribución de información que se requiere de los aspirantes. Que el Estado lleve a cabo el concurso conlleva operaciones burocráticas de empadronamiento (expresado en la documentación e inscripciones en instituciones) en manos de letrados. La realización del desfile, que supone labores de procedimiento y archivo, sustentada por 
el fisco se articula con la máxima autoridad simbólica que detenta el Estado como instancia de consagración (Bourdieu, 1993).

Al seleccionar a los aspirantes, los jurados como intermediarios les reconocen la dimensión estética que señalan como originalidad en las prendas y los valoran también como empresarios en el campo económico por lo cual requieren certificados de tal condición (un sitio de venta y plan de negocios) de que puede comercializar colecciones o lo podría hacer en próximas temporadas. El momento del desfile está supeditado al presente, según los evaluadores para quienes la marca constituye en cambio la visualización del futuro. Para uno de los diseñadores entrevistados en los videos, el concurso es la oportunidad para los jóvenes diseñadores de darse a conocer entre sus colegas. Desde la perspectiva de los organizadores, no sólo se trata de una oportunidad para ser conocidos sino más allá de los días que dura el evento que es el BAF Week sino como marcas en el sentido de ser empresas. Las instancias previas a la presentación en pasarela constituyen un compendio de cuestiones tratadas en este artículo como la significación de las fechas límites en la moda y de que forma el advenimiento de las mismas es experimentadas por los agentes: se les otorga veinte días a los finalistas para confeccionar todos los conjuntos. En esos días y en el curso del desfile, las visitas realizadas por estilistas dan cuenta de la cantidad de intermediarios que evalúan un bien como la vestimenta: fotógrafos, estilistas, coreógrafos para las pasadas de las modelos, DJs para la música y agentes de prensa.

\section{Comentarios conclusivos}

Si bien todos los individuos forman parte idealmente del orden capitalista actual, no todos adhieren o contemplan las máximas morales que supone incorporarse al mismo. En el campo de la moda, supone que los productores de ropa se orienten por un calendario pero no todos pueden contemplarlo o seguir el ritmo social que requiere producir dos colecciones anuales.

Mi objetivo en este artículo consistió en comprender como los diseñadores son reconocidos como marcas por agentes en el campo. Este reconocimiento es múltiple en el sentido de que son varios intermediarios quienes corroboran que son marcas, sin dejar de tener en cuenta su condición de diseñadores. Si bien estos intermediarios no desconocen la cuestión artística, sus dotes para producir un vestido original, el valor también se otorga a su venta y la misma debe ser sostenida no sólo en el presente sino anticipando temporadas próximas. Me propuse describir el proceso de profesionalización de los diseñadores para obtener el reconocimiento mencionado, el cual comprende varias instancias relativas a la producción y comercialización de la colección. Una de las instancias de este proceso es el cálculo expresado en la determinación de quién es el consumidor y cuál es el mercado al cual se orienta la indumentaria que producen. En relación al cálculo, otra instancia son los números que es la expresión que ellos utilizan para referirse a la ponderación de los costos fijos y variables de la confección.

En lo relativo a la comercialización de la colección, los espacios son los siguientes: el local o showroom propio, la consignación en tiendas multimarcas y la exhibición en desfiles realizados en eventos de moda. Respecto a estos tres espacios, lo que incorporan los di- 
señadores son los ritmos temporales propios de la moda que supone la división de la producción de vestimenta en temporadas.

En lo que respecta al concurso "Buenos Aires Diseña”, éste ofrece más que la posibilidad de realizar un desfile en uno de los eventos de moda organizados en CABA sino que constituye una instancia en la cual se aprehenden máximas relativas al cálculo y el tiempo expresadas en la preparación previa al desfile de los finalistas (junto con estilistas que los asesoran) y la asistencia a un curso orientado a impartir saberes relativos a los números. La descripción que llevó a cabo Bourdieu en "Argelia 60" acerca de los campesinos cabilios que, provenientes de entornes rurales, se incorporan a la sociedad capitalista me posiblitó reflexionar sobre dos nociones que tuve en cuenta al analizar el proceso señalado. En primer lugar, la aprehensión de la noción de cálculo relativo, a la percepción de un futuro abstracto y la evaluación cuantitativa de los beneficios implicadas en lo que el autor llama el "espíritu de cálculo". En segundo lugar, la incorporación a la sociedad capitalista que supone, para aquellos campesinos que detentan un empleo permanente, el poder dominar el futuro y adecuarse a un ritmo que es social. Salvando las distancias contextuales, la etnografía bourdeana me permitió profundizar en torno a una preocupación central entre los diseñadores: cómo este ritmo o tempo se expresa en el calendario bianual indicado.

\section{Notas}

1. Una periodista llamada Cati, redactora del suplemento "Moda y Belleza" La Nación reafirmó esta distinción respecto a los diseñadores: no es la moda pronta de una marca, fácil de usar. Tienen algo más elaborado, una cosa más intelectual, juegan con los cortes o un color. Seguidamente, le pregunté cómo distinguía tal distinción en los desfiles: la marca tiene cánones que se repiten, en el diseño de autor te vas a encontrar con una revisión del mismo diseñador, un poco de él con algo de la temporada que le sumó, pero con su morfología propia, en el arte reconoces la obra del autor sin que esté firmada, en el diseño ves al autor.

2. Conjunto de moldes que conforman las bases de una prenda, elaboradas manualmente con papel o mediante programas informáticos.

3. A estas ciudades se las llama las "cuatro capitales de la moda" pero también pueden señalarse la relevancia de otras urbes. En ellas se originan los nuevos estilos, exhibidos en colecciones bianuales, cuando determinadas audiencias (que incluyen críticos, editores, publicistas y compradores) las reconocen y legitiman en un proceso señalado por Fred Davis que incluye instancias como la difusión, incremento de la visibilidad hasta la saturación y obsolescencia (1992).

4. Cuando hablo de límites morales, me estoy basando en Michelle Lamont y Virag Molnar (2002) quienes los definen como distinciones conceptuales que los individuos utilizan para crear y sostener distancias sociales entre ellos y otros. Atendiendo a la separación entre lo sagrado y lo profano que Mary Douglas (1973) asociaba a la religión, lo sagrado como valor último es el diseño que, erigiendo a la ausencia de la copia, refuerza las diferencias entre quienes producen vestimenta. La copia, entre quienes entrevisté, era aquello de lo cual un diseñador debía mantenerse apartado y pretendía apartarse, al menos en el nivel del discurso. 
5. En dichos ritos, según Bourdieu (2001), se consagran socialmente diferencias de forma tal que aparecen como naturales para los agentes. Lo que se producen en estos actos es la santificación de un determinado estado de cosas o la atribución de investiduras a las personas. Mi interés en este artículo radica en comprender como se consagra a un diseñador como marca, sin dejar de reconocer otra investidura que es diseñador.

6. Gerente de marketing que ofrecía servicios de consultoría a diseñadores respecto a la construcción de marca y conformación de su negocio. Asimismo, intervenía como "curadora" en la selección de participantes en la feria "Puro Diseño". El fragmento corresponde a una entrevista realizada en el 2007, en su estudio situado en el barrio de Recoleta.

7. El CMD (Centro Metropolitano de Diseño) es una institución estatal creada en el 2001 que depende del Gobierno de la Ciudad de Buenos Aires.

8. El primero se caracteriza por estar conformado por productores quienes tienen como público a los mismos productores. El subcampo de la gran producción, por su parte, está guiado por la lógica del éxito y ganancia económica en el mercado (Bourdieu, 1990).

9. Productora (que también se reconoce como estilista) a quien entrevisté en un bar situado en el barrio de Belgrano en el 2015. Desde su perspectiva, el productor se ocupa de los aspectos operativos de un desfile que implicaba buscar una locación, contratar a los maquilladores, asistentes y peinadores. El estilista se dedica a los aspectos estéticos, ponderar cuales son las prendas a incluir en la colección según el concepto.

10. El lookbook es el catálogo virtual e impreso sumado a la filmación de la sesión fotográfica en la cual las modelos exhiben las prendas, en un estudio fotográfico o espacio abierto. 11. Recorrido transitado por las modelos a lo largo de la pasarela, en el curso de un desfile. 12. URL: https://www.crecemujer.cl/capacitacion/ideas-de-negocio/que-son-los-costosfijos-y-variables-en-mi-emprendimiento

13. Diseñadora argentina egresada de la Universidad del Salvador donde estudió escenografía. Trabajó en el departamento de producto de una empresa hasta iniciar su marca en el 2003. Actualmente tiene un único un local y ofrece como consultoría información sobre tendencias de temporada futuras.

14. Esquemas donde se detallan los detalles técnicos de una prenda como el tejido utilizado, las medidas de sus piezas y el detalle de avíos utilizados.

15. Consiste en la silueta de una prenda, que depende de la forma en la cual está dispuesta la moldería.

\section{Bibliografía}

Bourdieu, P. (1990). "Alta costura y Alta cultura”. Sociología y Cultura. México. Grijalbo. . (1990). "El campo literario. Prerrequisitos críticos y principios de método".

Criterios La Habanna. Núm 25-28. pp 20-42.

Grijalbo. . (1990). "Algunas propiedades de los campos”. Sociología y Cultura. México.

. (1997). "Espíritus de Estado. Génesis y estructura del campo burocrático”, en

Razones Prácticas. Sobre la teoría de la acción. Barcelona. Anagrama. . (1998) La Distinción. Criterio y bases sociales del gusto. Madrid. Taurus. 
. (2001). Qué significa hablar. Madrid. Akal Editores.

. (2002). Las estructuras sociales de la Economía. Buenos Aires. Editorial Manantial.

(2006). Argelia 60. Estructuras económicas y estructuras temporales. Buenos Aires. Editorial Siglo XXI.

Callon, M. (2008). "Los mercados y la performatividad de las ciencias económicas". Apuntes de Investigación Cecyp. Tema Central Economía. No 14.

Davis, F. (1992). Fashion, Culture and Identity. University of Chicago Press.

Douglas, M. (1973) Pureza y Peligro. Un análisis de los conceptos de contaminación y tabú. México. Siglo XXI editores.

Lamont, M. y Molnar, V. (2002). The Study of Boundaries in the Social Sciences. Annual Review of Sociology. Vol 28: 167-95.

Marion, G. (2006). "Research Note: Marketing ideology and criticism: Legitimacy and legitimization". Marketing Theory. Vol 6. pp 245-262.

Rocamora, A. (2002). "Fields of Fashion. Critical Insights into Bourdieu's Sociology of Culture". Journal of Consumer Culture. Vol 2(3): 341-362.

Rutz, H. (1992). The Politics of Time. AES Monography Number 4.

Thompson, E. (1989). "Tiempo, disciplina de trabajo y capitalismo industrial". Tradición, revuelta y conciencia de clase. Estudios sobre la crisis en la sociedad industrial. México. Grijalbo.

Weber, M. (1993). La ética protestante y el espíritu del capitalismo. Barcelona. Ediciones Península.

Weller, S. (2007). “Fashion as viscous knowledge: fashion's role in shaping trans-national garment production”. Journal of Economic Geography. Vol 7. pp 39-66.

\begin{abstract}
The aim of this article is to describe the process by which a group of costume designers are recognized as brands by other fashion agents with whom they are linked to make and display their seasonal collections: modelers, marketing consultants, stylists, fashion producers and owners of multibrand stores.

My purpose is to understand in what ways, in the course of this process, the designers incorporate the "calculation" in their conduct as an ethic that, as defined by Pierre Bourdieu, is constitutive of the capitalist economy and implies the temporary perception of the future distanced from the immediate present that characterizes precapitalist economies.Taking into account my ethnographic field work carried out between 2005 and 2018, I will analyze how they apprehend such ethics when marketing the collections, in spaces such as retail venues, multibrand stores and biannual fashion events.
\end{abstract}

Keywords: calculation - time - fashion - design - collection - Argelia 60.

Resumo: O objetivo deste artigo consiste em descrever o processo pelo qual um grupo de desenhistas de indumentária é reconhecido como marcas por outros agentes no campo da 
moda com quem se associam para fazer e exibir suas coleções de estação: modelistas, consultores em marketing, estilistas e produtores de paradas, e donos de lojas multimarcas. Meu propósito é entender do que formas, no curso deste processo, os desenhistas incorporam o "cálculo" em seu comportamento como uma ética que, de acordo com Pierre Bourdieu, é constituinte da economia capitalista e insinua a percepção temporária do futuro distanciado do presente imediato que caracteriza as economias precapitalistas. Tendo em conta meu trabalho de campo etnográfico executado entre 2005 e 2018, eu analisarei como eles apreendem estas éticas ao comercializar as coleções, em espaços como lojas de venda ao público, lojas multimarcas e eventos bianuais de moda.

Palavras chaves: cálculo - tempo - moda - desenho - coleção.

[Las traducciones de los abstracts fueron supervisadas por el autor de cada artículo] 